\title{
Knowledge and attitudes about emergency contraception among pharmacist and physician preceptors in South Carolina
}

This article was published in the following Dove Press journal:

Open Access Journal of Contraception

24 August 2010

Number of times this article has been viewed

\author{
Sarah Shrader ${ }^{1,2}$ \\ Ann M Rodden' \\ Lisa Carroll ${ }^{3}$ \\ Lars E Peterson' \\ 'Medical University of South \\ Carolina, Department of Family \\ Medicine, Charleston, SC, USA; \\ 2South Carolina College of Pharmacy, \\ Department of Clinical Pharmacy \\ and Outcomes Sciences, Charleston, \\ SC, USA; ${ }^{3}$ Spartanburg Regional \\ Family Medicine Residency Program, \\ Department of Family Medicine, \\ Spartanburg, SC, USA
}

Background: Emergency contraception (EC) may reduce unintended pregnancies if patients are informed and have access. A great deal of medical education occurs during medical and pharmacy training community clerkships. This study concurrently assesses knowledge and attitudes about EC between community physician and pharmacist preceptors who prescribe/ dispense EC.

Study design: Electronic survey of demographic information, knowledge-based, and attitude questions related to EC was completed by 182 (36.6\% response rate) South Carolina community physicians and pharmacists who precept students. Comparisons were performed using chi-square or Fischer's exact test.

Results: In the study population, approximately $62 \%$ of pharmacists dispense EC while only $28 \%$ of physicians prescribe it. More physicians than pharmacists believe repetitive use is not harmful (48.3\% vs $28.0 \%, P=0.010$ ), while more pharmacists believe it causes birth defects (22.6\% vs $7.9 \%, P=0.008)$.

Conclusion: Overall, both physicians and pharmacists have poor knowledge about EC. Further education for both groups may be needed so future physicians and pharmacists are not taught incorrectly during their training and so patient access is not hampered by prescriber misunderstanding.

Keywords: emergency contraception, levonorgestrel, pharmacist, physician

\section{Introduction}

Emergency contraception (EC) is an important and controversial issue in health care. EC to prevent pregnancy after intercourse has the potential to reduce unintended pregnancies in the United States (US). According to the latest national family planning statistics, from 2002, 35\% of births in the US are unintended with rates much higher in women under 18 years of age and in all women with an education less than a high school diploma. The unintended pregnancy rates for those populations are approximately $60 \% .{ }^{1}$ More specifically, South Carolina ranks as having the 18th highest teen pregnancy rate in the nation. ${ }^{2}$

In 2006, the Food and Drug Administration (FDA) approved nonprescription status of the progestin-only EC containing levonorgestrel (LNG-EC), which allows any person, with valid identification, who is 18 years and older, to purchase nonprescription LNG-EC. Subsequently, in 2009, the FDA reduced the age for purchase of nonprescription status to any person 17 years of age and older. Women may prefer to have a prescription from a medical provider, but only those under 17 years of age are required to have a valid prescription for a pharmacist to dispense EC.
Medical University of South Carolina Department of Family Medicine, 295 Calhoun St. FM322A, Charleston, SC 29425 , USA

Tel + I-843 7923624

Fax +I-8437920436

Email shrader@musc.edu 
Considering this shift to nonprescription status, both physicians and pharmacists may directly impact access to this form of EC. Responsibilities of these health care providers include providing prescriptions, dispensing the medication (prescription and nonprescription), providing patient education, and in some cases providing education about EC to medical and pharmacy students whom they precept. After LNG-EC was approved for nonprescription status, the manufacturer, many pharmacy organizations, and EC advocate groups provided major educational campaigns for pharmacists. Previous studies have examined attitudes and knowledge of physicians and pharmacists about EC. ${ }^{3-8}$ The majority of the results suggest there are myths surrounding EC. Knowledge of EC was generally average to poor and improvements in knowledge and attitudes for both pharmacists and physicians may be warranted.

To date, no study has performed a concurrent assessment of knowledge and attitudes of community physicians (specifically family medicine physicians) and community/ outpatient pharmacists. In addition, community physicians and pharmacists who precept for medicine and pharmacy academic programs have the potential to influence student training and prescription/dispensing habits of these future physicians and pharmacists. The purpose of this study was to concurrently assess knowledge and attitudes about EC of both community physicians and community pharmacists practicing in South Carolina who are also preceptors for the Medical University of South Carolina (MUSC). The primary objective was to determine if there were knowledge gaps and misinformation within the groups. The secondary objective was to determine differences in these areas when comparing the two professional groups.

\section{Methods}

\section{Survey}

A survey about emergency contraception, specifically LNG-EC, was developed from a previous survey reported in the literature; modifications were implemented based on the primary study objective and updated information. ${ }^{7}$ The survey focused on basic demographics, prescribing/dispensing habits, knowledge-based questions, and attitude questions about EC. The correct answers to the knowledge questions were based on information from the American College of Obstetricians and Gynecologists practice bulletin on EC and from updated information released regarding mechanism of action. ${ }^{9,10} \mathrm{~A}$ small group of family physicians and community pharmacists piloted the survey and offered feedback, which provided the basis for revisions.

\section{Study design/objective}

Participants consisted of two distinct groups: (1) community pharmacists who precept in the College of Pharmacy Clerkship at the MUSC; and (2) family medicine physicians who precept in the MUSC Family Medicine Rural Clerkship or at family medicine residency programs throughout South Carolina. The family medicine residency programs included faculty and residents in the survey since both actively teach medical students during clerkships. The final survey was distributed to the study participants by means of an electronic survey system (Surveymonkey Software ${ }^{\circledR}$, Portland, OR). Two reminders to complete the survey were sent over a two-month period (data collection January-February, 2009). Participants voluntarily and anonymously submitted the survey. At the completion of the study, the survey portal offered educational information about EC along with website links that the participant could access, if desired.

\section{Statistical analysis}

Descriptive statistics were used for demographic data analysis. Comparisons were made with either the chi-square test or Fischer's exact test when expected cell sizes were less than five. With a sample size of 93 pharmacists and 89 physicians, we had power equal to 0.80 to detect an effect size of 20 percent difference between groups. All statistical analyses were performed with SAS v9.2 (Cary, NC). This study was considered exempt and approved by the MUSC institutional review board.

\section{Results}

Almost 500 community physicians and pharmacists in South Carolina were sent the survey and 182 completed it, representing a response rate of $36.6 \%$ (Table 1). Most physician responders had practiced fewer than 5 years while pharmacist responders had more years of experience $(P<0.001)$. In both groups, the majority did not practice in small, rural-sized populations. Approximately $28 \%$ of physicians prescribed EC while about $62 \%$ of pharmacists reported dispensing EC (Table 2). Of those who did not prescribe EC, most physicians reported that patients did not request it. Another quarter of the physicians reported that moral or religious reasons precluded them from prescribing EC. The pharmacist responders reported similar reasons for not dispensing EC with a higher percentage holding moral/ religious objections. Physicians and pharmacists had the option to provide comments regarding their reasons for not prescribing or dispensing EC and a variety of responses were recorded (Table 3). 
Table I Characteristics of the participating physician and pharmacist responders

\begin{tabular}{|c|c|c|c|c|}
\hline & Physicians & Pharmacists & Total & $P$ value \\
\hline Number of surveys sent & 253 & 244 & 497 & \\
\hline Responded & $35.2 \%(89)$ & $38.1 \%(93)$ & $36.6 \%(182)$ & $0.497^{\mathrm{a}}$ \\
\hline Gender & & & & $0.077^{\mathrm{a}}$ \\
\hline Male & $48.3 \%(43)$ & $46.2 \%(43)$ & $47.3 \%(86)$ & \\
\hline Female & $51.7 \%(46)$ & $53.8 \%(50)$ & $52.7 \%(96)$ & \\
\hline Years practicing & & & & $<0.00 I^{\mathrm{b}}$ \\
\hline$\leq 5$ & $60.7 \%(54)$ & $21.5 \%(20)$ & $40.7 \%(74)$ & \\
\hline $6-10$ & $10.1 \%(9)$ & $18.3 \%(17)$ & $14.3 \%(26)$ & \\
\hline $\mathrm{II}-20$ & $11.2 \%(10)$ & $19.4 \%(18)$ & $15.4 \%(28)$ & \\
\hline $21-30$ & $\mathrm{I} 2.4 \%(\mathrm{II})$ & $23.7 \%(22)$ & $18.1 \%(33)$ & \\
\hline$\geq 30$ & $5.6 \%(5)$ & $17.2 \%(16)$ & $1 \mathrm{I} .5 \%(2 \mathrm{I})$ & \\
\hline Practice community size $^{c}$ & & & & $0.009^{b}$ \\
\hline$<10,000$ & $2.3 \%(2)$ & $11.8 \%(1 \mathrm{I})$ & $7.2 \%(13)$ & \\
\hline $10,000-50,000$ & $35.2 \%(3 I)$ & $44.1 \%(4 I)$ & $39.8 \%(72)$ & \\
\hline$>50,000$ & $62.5 \%(55)$ & $44.1 \%(4 I)$ & $53.0 \%(96)$ & \\
\hline
\end{tabular}

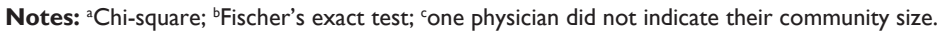

Of the $28 \%$ of physician responders who prescribed EC, almost a quarter of those did not prescribe $\mathrm{EC}$ in the past year (Table 2). Sixty percent wrote one to five prescriptions for EC while less than $20 \%$ wrote more than 5 prescriptions for EC in the past year. In contrast, $62 \%$ of the pharmacist responders dispensed EC and approximately a third dispensed more than 6 prescriptions in the past year. Only $10 \%$ of those who stated they dispensed EC did not do so in the past year. The majority of pharmacist and physician responders reported feeling comfortable discussing EC with patients, however, about a third of physicians and $20 \%$ of pharmacists did not feel comfortable doing so.

Knowledge-based questions about EC consisted of those listed in Table 4 with correct answers noted in italics. More physician than pharmacist responders appropriately identified the mechanism of action, but this difference was not statistically significant $(P=0.065)$. The majority of both groups identified that EC inhibits implantation, which is not the primary mechanism of action. The majority of pharmacists and physicians did not know that LNG-EC is indicated up to

Table 2 Prescribing/dispensing habits of community physician and pharmacist responders who precept students in South Carolina

\begin{tabular}{|c|c|c|c|}
\hline & Physician responders \%/(n) & Pharmacist responders \%/(n) & $P$ value \\
\hline Write prescription for/dispense EC & & & $<0.00 I^{\mathrm{a}}$ \\
\hline Yes & $28.1 \%(25)$ & $62.4 \%(58)$ & \\
\hline No & $71.9 \%(64)$ & $37.6 \%(35)$ & \\
\hline Reason not prescribing/dispensing among & & & $<0.00 I^{\mathrm{b}}$ \\
\hline \multicolumn{4}{|l|}{ those not prescribing/dispensing ${ }^{c}$} \\
\hline No patient requests & $58.7 . \%(37)$ & $42.9 \%(15)$ & \\
\hline Moral or religious reasons & $22.2 \%(14)$ & $31.4 \%(\mathrm{II})$ & \\
\hline Not sure & $1.6 \%(1)$ & $2.9 \%(I)$ & \\
\hline Other & $17.5 \%(11)$ & $22.9 \%(8)$ & \\
\hline Number of scripts written/dispensed & & & $0.007^{b}$ \\
\hline \multicolumn{4}{|l|}{ in last year by those prescribing/dispensing } \\
\hline 0 & $24.0 \%(6)$ & $10.3 \%(6)$ & \\
\hline $1-5$ & $60.0 \%(15)$ & $37.9 \%(22)$ & \\
\hline$>6$ & $16.0 \%(4)$ & $51.7 \%(30)$ & \\
\hline Comfort in discussing EC & & & $0.114^{b}$ \\
\hline Very comfortable & $33.7 \%(30)$ & $41.9 \%(39)$ & \\
\hline Comfortable & $36.0 \%(32)$ & $37.0 \%(34)$ & \\
\hline Uncomfortable & $24.7 \%(22)$ & $11.8 \%(11)$ & \\
\hline Very uncomfortable & $5.6 \%(5)$ & $9.7 \%(9)$ & \\
\hline
\end{tabular}

Notes: ${ }^{a}$ Chi-square; ' ${ }^{\circ}$ ischer's Exact Test; 'One physician did not answer this question. Abbreviation: EC, emergency contraception. 
Table 3 Selected comments of the participating preceptor physician and pharmacist responders regarding reasons why they did not prescribe/dispense EC

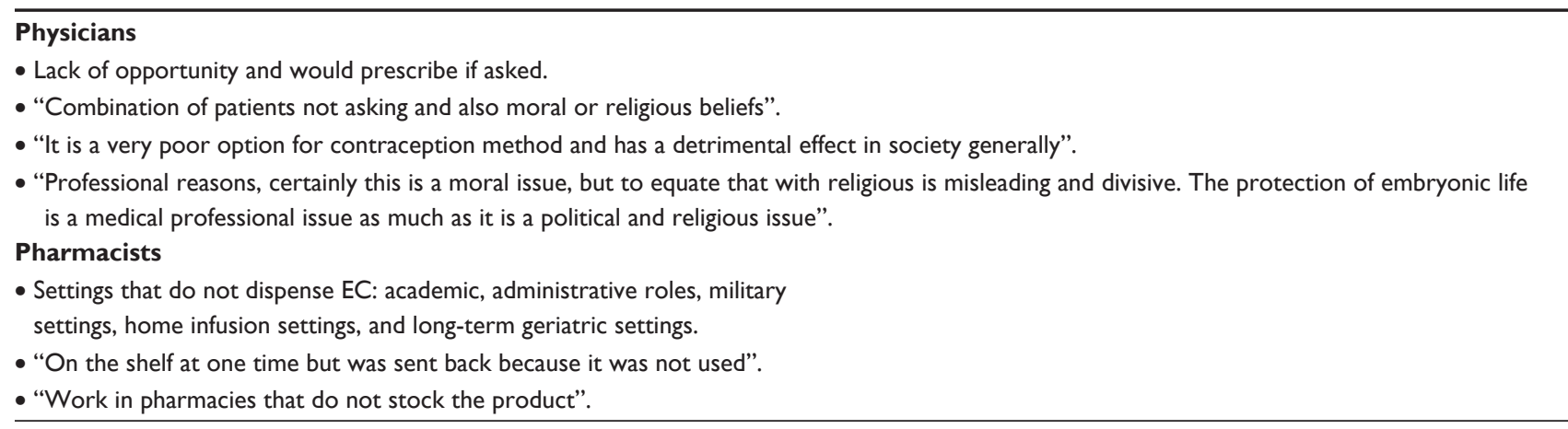

120 hours after intercourse. Both groups correctly identified the most common side effect of EC as nausea. Almost half of physician responders appropriately answered that repeated EC use does not harm one's health compared with less than a third of pharmacists answering this way $(P=0.010)$. In addition, less than $8 \%$ of physicians incorrectly answered that EC use during pregnancy will cause birth defects compared with $23 \%$ of pharmacists $(P=0.008)$.

There were no differences between the groups in attitudes about whether a physician consultation should be required prior to receiving EC. Interestingly about $50 \%-60 \%$ of both responder groups stated that women should be required to have a physician consultation before receiving EC even though it is currently available over the counter for those 17 years of age and older. The majority of physicians and pharmacists appropriately stated that increasing EC access will not lead to decreased use of other forms of contraception.

\section{Discussion}

Knowledge was poor and attitudes about misperceptions were high in both physician and pharmacist responders regarding EC. Improvements are needed for both groups of healthcare professionals. In addition, the results of this study suggest there may be differences in knowledge and attitudes among community physicians and pharmacists regarding EC. Overall, the community pharmacists appeared less knowledgeable and had more attitudinal misperceptions regarding EC, specifically LNG-EC. These differences occurred despite the fact that more pharmacists than physicians surveyed actually prescribed/dispensed EC, and the pharmacists that filled LNG-EC requests filled many more than prescribed by physician responders. The wording on the survey may have misled some participants when choosing the timing for administration of EC. The use of the technical term 'indication' may have led some participants, particularly pharmacists, to put 72 hours if they are dispensing without a prescription since the FDA labeling states this timeframe, even though it has been proven to be effective up to 120 hours. In addition, significantly more pharmacists incorrectly answered that repeat use of EC may be harmful to the patient and furthermore, use of EC during pregnancy may cause birth defects.

A theory to explain the differences in responses observed between the physician and pharmacist groups in this study could be related to differences in the study populations. Many more pharmacists had been practicing for 20 years or more, compared to the majority of physicians who had less than five years of professional practice. Potentially, newer health care practitioners may be more aware of attitudes concerning EC and are more knowledgeable about it because these were taught in medical and pharmacy school. In contrast, practitioners with more experience likely did not receive any formal education on EC and they are only aware of this practice through self-learning and continuing education. This may have implications for future education targeting these specific groups (newer versus experienced practitioners) and also warrants further investigation.

There is limited information on pharmacist and physician knowledge and attitudes about EC; however, these results are similar to other published data. Wallace and colleagues surveyed family physicians within a single academic department and found low levels of knowledge about EC. ${ }^{7}$ Previous studies have reported that pharmacists within specific states had low to average results on knowledge-based surveys. ${ }^{5}$ In addition, studies have used "mystery shopper" methods to ask knowledge-based questions regarding EC of pharmacists within a specific region, however, the main objective of these studies was to determine availability of EC. ${ }^{3,6}$ Results of these studies suggested that pharmacist knowledge about EC was low and could be improved. ${ }^{3,6}$ In contrast, a citywide survey 
Table 4 Knowledge base of emergency contraception information among community physician and pharmacist responders who precept students in South Carolina

\begin{tabular}{|c|c|c|c|}
\hline & Physician responders \%/(n) & Pharmacist responders $\% /(n)$ & $P$ value ${ }^{a}$ \\
\hline Most likely MOA & & & 0.063 \\
\hline Prevent/delaying ovulation & $23.6 \%(2 I)$ & $\mathrm{II} .8 \%(\mathrm{II})$ & \\
\hline Aborting pregnancy & $0.0 \%(0)$ & $2.2 \%(2)$ & \\
\hline Inhibiting implantation & $70.8 \%(63)$ & $82.8 \%(77)$ & \\
\hline Not sure & $5.6 \%(5)$ & $3.2 \%(3)$ & \\
\hline \multicolumn{3}{|l|}{ following intercourse } & 0.408 \\
\hline$<24$ & $11.2 \%(10)$ & $16.1 \%(15)$ & \\
\hline$<72$ & $75.3 \%(67)$ & $75.3 \%(70)$ & \\
\hline$<120$ & $6.7 \%(6)$ & $2.2 \%(2)$ & \\
\hline Not sure & $6.7 \%(6)$ & $6.5 \%(6)$ & \\
\hline Most commonly reported side effect & & & 0.706 \\
\hline Diarrhea & $1.1 \%(1)$ & $0.0 \%(0)$ & \\
\hline Nausea & $74.2 \%(66)$ & $67.7 \%(63)$ & \\
\hline Headache & $2.2 \%(2)$ & $2.2 \%(2)$ & \\
\hline Irregular vaginal spotting & $11.2 \%(10)$ & $14.0 \%(\mid 3)$ & \\
\hline Not sure & $11.2 \%(10)$ & $16.1 \%(15)$ & \\
\hline Repeated EC use can harm one's health & & & 0.010 \\
\hline Agree & $16.9 \%(15)$ & $31.2 \%(29)$ & \\
\hline Neither & $34.8 \%(31)$ & $40.9 \%(38)$ & \\
\hline Disagree & $48.3 \%(43)$ & $28.0 \%(26)$ & \\
\hline EC use during pregnancy can cause & & & 0.008 \\
\hline \multicolumn{4}{|l|}{ birth defects } \\
\hline Agree & $7.9 \%(7)$ & $22.6 \%(2 I)$ & \\
\hline Neither & $25.8 \%(23)$ & $30.1 \%(28)$ & \\
\hline Disagree & $66.3 \%(59)$ & $47.3 \%(44)$ & \\
\hline Increased access decreases & & & 0.392 \\
\hline \multicolumn{4}{|l|}{ use of other contraception } \\
\hline Agree & $15.7 \%(14)$ & $20.4 \%(19)$ & \\
\hline Neither & $23.6 \%(2 I)$ & $29.0 \%(27)$ & \\
\hline Disagree & $60.7 \%(54)$ & $50.5 \%(47)$ & \\
\hline Should require physician & & & 0.493 \\
\hline \multicolumn{4}{|l|}{ consultation prior to receiving EC } \\
\hline Agree & $58.4 \%(52)$ & $49.5 \%(47)$ & \\
\hline Neither & $16.9 \%(15)$ & $20.4 \%(19)$ & \\
\hline Disagree & $24.7 \%(22)$ & $30.1 \%(27)$ & \\
\hline
\end{tabular}

Notes: ${ }^{a}$ Fischer's exact test; Correct answers italicized.

Abbreviations: MOA, mechanism of action; EC, emergency contraception.

of pharmacists in San Francisco demonstrated this group had above average knowledge about EC. ${ }^{4}$ The majority of pharmacists that participated in the study received an hour-long education session before the survey, which may demonstrate that delivery of EC education programs increases knowledge. ${ }^{4}$ Finally, a recent sham patient caller study identified that the majority of pharmacies in the Los Angeles area had increased availability of EC and most pharmacists answered questions appropriately. However, there were still several instances when incorrect information was provided about $\mathrm{EC}$ to the callers. ${ }^{11}$

The present study is timely on the issue of $\mathrm{EC}$ and has important implications for the future. The majority of the previous studies related to knowledge and attitude about EC were conducted more than three years ago and since the publication of these studies new information has been made available and EC has gained nonprescription status. This study included community pharmacists and physicians, which are two populations of health care practitioners that may have the widest influence on access to EC. The study population may be reflective of general prescribing/ dispensing trends in the US, with more pharmacists dispensing EC than physicians prescribing it, as nonprescription status has recently expanded to patients 17 years of age and greater. To our knowledge, this is the first concurrent 
assessment using statistical analysis of different health care professions. In addition, the physician and pharmacist groups were also preceptors for medical university academic programs, potentially having an influence on student perceptions and knowledge of EC. This study identified that education about EC, specifically LNG-EC, should be increased for both community pharmacists and community physicians.

This study is not without limitations. Despite the fact that this study included a larger number of participants than other published findings, the response rate for the survey remained low and may not be representative of all community physicians and pharmacists in South Carolina since information about nonresponders was unavailable. Likewise, the study participants were from one state, which makes it difficult to generalize the findings on a broader scale. Results via a self-reported survey have the potential for recall bias and responses may not be reflective of actual behaviors. Finally, the differences in the demographics of the groups, especially related to the number of years in practice, may have influenced the results. All of these limitations could be considered as areas for future research related to EC.

\section{Conclusion}

This study suggests there are differences in knowledge and attitudes between community physician and pharmacist preceptors in South Carolina. More pharmacists than physicians in this study prescribed/dispensed EC. Of those that prescribe/dispense, pharmacist responders filled more requests for $\mathrm{LNG}-\mathrm{EC}$ than physician responders prescribed in the past year. However, significantly fewer pharmacists are knowledgeable about dosing options (eg, timeframe) for LNG-EC compared with physicians. Significantly more pharmacist responders, compared with physicians, have common misperceptions about EC. These misperceptions and knowledge deficits may limit access to EC for patients and may influence incorrect teaching methods about EC for students. Overall, in both groups, knowledge about EC was low, suggesting a need for increased education for both of these health care professional groups since they currently prescribe/dispense EC to women in the community and are teaching our future physicians and pharmacists.

\section{Disclosures}

The authors disclose no conflicts of interest.

\section{References}

1. Chandra A, Martinez GM, Mosher WD, Abma JC, Jones J. Fertility, family planning, and reproductive health of U.S. women: Data from the 2002 national survey of family growth. National Center for Health Statistics. Vital Health Stat. 2005;25:1-160.

2. South Carolina Department of Health and Environmental Control. Available at: www.scdhec.gov/co/phsis/biostatistics/index.asp?page=bio. Accessed on August 21, 2009.

3. French AC, Kaunitz AM. Pharmacy access to emergency hormonal contraception in Jacksonville, FL: a secret shopper survey. Contraception. 2007;75:126-130.

4. El-Ibiary SY, Raine T, McIntosh J, Darney PD, Harper CC. Pharmacy access to emergency contraception: perspectives of pharmacists at a chain pharmacy in San Francisco. J Am Pharm Assoc. 2007;47:702-710.

5. Borrego ME, Short J, House N, Gupchup G, Naik R, Cuellar D. New Mexico's pharmacists' knowledge, attitudes, and beliefs toward prescribing oral emergency contraception. J Am Pharm Assoc. 2006; 46:33-43.

6. Bennett W, Petraitis C, D'Anella A, Marcella S. Pharmacists' knowledge and the difficulty of obtaining emergency contraception. Contraception. 2003;68:261-267.

7. Wallace JL, Wu J, Weinstein J, Gorenflo DW, Fetters MD. Emergency contraception: knowledge and attitudes of family medicine providers. Fam Med. 2004;36:417-422.

8. Beckman LJ, Harvey SM, Sherman CA, Petitti DB. Changes in providers' views and practices about emergency contraception with education. Obstet Gynecol. 2001;97:942-946.

9. Emergency contraception. ACOG Practice Bulletin No. 69. American College of Obstetricians and Gynecologists. Obstet Gynecol. 2005;106: 1443-1452.

10. International Consortium for Emergency Contraception. Available at: www.cecinfo.org/publications/policy.htm. Accessed August 21, 2009.

11. Nelson AL, Jaime CM. Accuracy of information given by Los Angeles County pharmacies about emergency contraceptives to sham patient in need. Contraception. 2009;79:206-210.
Open Access Journal of Contraception

\section{Publish your work in this journal}

Open Access Journal of Contraception is an international, peerreviewed, open access, online journal, publishing original research, reports, reviews and commentaries on all areas of contraception. In addition to clinical research, demographics and health-related aspects, the journal welcomes new findings in animal and preclinical studies

\section{Dovepress}

relating to understanding the biological mechanisms and practical development of new contraceptive agents. The manuscript management system is completely online and includes a very quick and fair peer-review system. Visit http://www.dovepress.com/testimonials.php to read real quotes from published authors. 